\title{
Anticholinergics in Adult-Onset Focal Dystonia
}

\author{
ANTHONY E. LANG, MICHAEL P. SHEEHY, and C. DAVID MARSDEN
}

SUMMARY: Anticholinergics are one of the most common treatments used in adultonset focal dystonias although their general efficacy has not been proven. We have investigated the effects of intravenous administration of atropine, benztropine and chlorpheniramine, in comparison to normal saline, in 20 patients with adult-onset focal dystonias (spasmodic torticollis (9), cranial dystonia (6), writer's cramp (5)), and have retrospectively reviewed the notes of 78 patients (spasmodic torticollis (38), cranial dystonia (25), writer's cramp (15)), who had received chronic oral anticholinergic therapy in varying doses at some time in the past. Patients with spasmodic torticollis and writer's cramp showed no consistent change with any of the intravenous drugs,

RÉSUMÉ: Les anticholinergiques sont souvent le traitement de choix des dystonies focales à début adulte même si leur efficacité n'a pas été prouvée. Nous avons comparé l'effet de l'administration intraveineuse d'atropine, de benztropine et de chlorphéniramine avec celui du salin chez 20 patients avec dystonie focale à début tardif $(9$ torticollis spasmodiques, 6 dystonies crâniennes, 5 crampes des écrivains). Nous avons également étudié rétrospectivement les dossiers de 78 patients (38 torticollis spasmodiques, 25 dystonies crâniennes et 15 crampes des écrivains) qui avaient reçu une thérapeutique aux anticholinergiques dans le passé. Les patients avec torticollis spasmodiques ou crampes des écrivains ne montrèrent while the few with cranial dystonia who improved usually did so at the expense of drug-induced sedation. The natural variability of these disorders was evident in the response to normal saline, which caused changes in the scores for severity of the involuntary movements of $20 \%$ or more in some patients. Only 8 of the patients who had received chronic oral therapy obtained more than mild benefit, and in 3 of them this improvement was transient. We conclude that cholinergic mechanisms are not of general or prime importance in the pathogenesis of adult-onset focal dystonias. However, each new patient warrants a trial of chronic oral anticholinergic therapy in view of the occasional useful responses obtained with these drugs.

aucun changement constant avec les traitements intraveineux. En ce qui concerne les quelques patients avec dystonie crânienne qui s'améliorèrent, ce le fut souvent au dépens d'une sédation secondaire aux médicaments. La variabilité naturelle de ces maladies fut évidente à l'épreuve au salin, car certains patients ont modifié leur réponse d'au moins 20\%. De tous les patients ayant reçu une thérapie sur base chronique, seuls 8 se sont légèrement améliorés, dont 3 de façon très transitoire. Nous concluons que les mécanismes cholinergiques ne sont pas d'importance générale ou primaire dans la pathogénèse de ces maladies dystoniques à début tardif. Chaque patient mérite cependant un essai thérapeutique.
From the University Department of Neurology, Institute of Psychiatry, de Crespigny Park, Denmark Hill, London SE5, 8AF, U.K.

Requests for reprints to: Dr. A.E. Lang, Division of Neurology, Toronto Western Hospital, 399 Bathurst Street, Toronto, Ontario, Cunada.

\section{INTRODUCTION}

The causes of the primary dystonias are unknown. Pathological investigations to date have been unrewarding (Zeeman, 1970) and pharmacological mechanisms remain controversial. Similar dystonic movements and postures are seen with well-described basal ganglia pathology, and drugs which alter neurotransmitters concentrated in the basal ganglia may cause both acute (Marsden et al, 1975) and tardive dystonia (Burke et al, 1982). These facts favour the possibility that idiopathic dystonia is due to basal ganglia disease.

Intravenous administration of anticholinergic or anticholinergic/antihistamine drugs abolishes acute dystonic reactions both in man and in haloperidol-susceptible Papio papio baboons (Meldrum et al, 1977). In addition, Fahn (1982) recently has reported marked benefit using very high doses of benzhexol in some young patients with idiopathic torsion dystonia. The response of acute dystonic reactions to intravenous anticholinergics and the results with high dose oral anticholinergic therapy encouraged us to study the effects of intravenous anticholinergic/antihistaminic drugs on various forms of adult-onset focal dystonia, and to retrospectively review the effects of chronic oral anticholinergic therapy in the same group of disorders. The conditions studied were cranial dystonia (Meige's disease, blepharospasm oro-mandibular dystonia, or Brueghel's syndrome) (Marsden, 1976), spasmodic torticollis, and writer's cramp. The inclusion of these disorders under "adult-onset focal dystonia" is purely for descriptive purposes (Marsden, 1976a) and does not imply a common pathological or biochemical mechanism.

The drugs chosen for study intravenously were benztropine, atropine, and chlorpheniramine, all of which were compared to control injections of 
normal saline. Benztropine has potent central anti-muscarinic properties and a high capacity to block dopamine (DA) reuptake (Coyle \& Snyder, 1969). Atropine is a classical anticholinergic which lacks this effect on DA reuptake (Fuxe et al, 1970). Chlorpheniramine has potent antihistaminic, but less active anticholinergic properties than the other two drugs.

\section{METHODS}

\section{Acute Intravenous Study}

20 patients with various forms of idiopathic focal or segmental adultonset dystonia were studied. Causes of symptomatic dystonia had been excluded by appropriate investigation in every case. All were otherwise normal neurologically and were in good health; none had a family history of any similar disorder. One patient included under spasmodic torticollis also had dystonia involving trunk and shoulder girdle, and one patient with dystonic writer's cramp had segmental dystonia involving the other arm, face and neck. Two patients, both with dystonic writer's cramp, taking oral anticholinergics stopped these drugs 24 hours prior to and during the trial period. One patient with cranial dystonia was taking a neuroleptic (tetrabenazine) and this was continued unaltered throughout the study. The other patients were on no drug therapy at the time of study.

Each patient was treated on separate days with intravenous injections of atropine $0.6 \mathrm{mg}$, benztropine $2 \mathrm{mg}$, chlorpheniramine $10 \mathrm{mg}$., and normal saline in random order. These dosages were chosen as representing the standard, usually maximum, single parenteral dose used in the routine clinical management of other conditions. One cranial dystonia patient who developed marked somnolence in response to benztropine $2 \mathrm{mg}$., was given lower doses of the other active agents (atropine $0.125 \mathrm{mg}$., chlorpheniramine $2.5 \mathrm{mg}$ ). Despite the lower dose of these latter agents she experienced similar but milder sedation.

The severity of the patients' abnormal movements was scored three times during the one hour before injection

TABLE 1

\section{SPASMODIC TORTICOLLIS RATING SCALE}

Rate turn plus tilt, for both tonic posture and clonic movements, to right or to left.

Score $0=0^{0}$

$$
\begin{array}{ll}
1=1-15^{\circ} & 4=45-60^{\circ} \\
2=15-30^{\circ} & 5=60-75^{\circ} \\
3=30-45^{\circ} & 6=75-90^{\circ}
\end{array}
$$

Add rating for sagittal deviation (antecollis or retrocollis)

$$
\begin{array}{ll}
0=\text { absent } & 2=\text { moderate } \\
1=\text { mild } & 3=\text { severe }
\end{array}
$$

Add rating for dystonia elsewhere; severity factor $x$ provoking factor for each part affected.

\section{SEVERITY FACTOR}

$0=$ no dystonia present

1 = slight dystonia, but not causing impairment. Clinically insignificant

$2=$ mild (not interfering with basic function)

$3=$ moderate (disabling, but not eliminating basic function)

\section{PROVOKING FACTOR}

$0=$ no dystonia at rest or action

$1=$ dystonia on particular action

$2=$ dystonia on many actions

$3=$ dystonia on action of distant part of the body

$4=$ dystonia present at rest

$4=$ severe (presents basic function)

TABLE 2

CRANIAL DYSTONIA RATING SCALE

Rate: Severity and

$$
\begin{aligned}
& 0=\text { nil } \\
& 1=\text { slight } \\
& 2=\text { mild (not interfering }
\end{aligned}
$$

For: Upper face

Also score Vision

$$
\begin{array}{ll}
0=\text { normal } & 0=\text { normal } \\
1=\text { rarely troubled } & 1=\text { slurred } \\
2=\begin{array}{l}
\text { can't drive } \\
\text { or read }
\end{array} & 2=\begin{array}{l}
\text { dysarthric but } \\
\text { intelligible }
\end{array} \\
3=\begin{array}{l}
\text { can't cross roads } \\
\text { or leave house }
\end{array} & 3=\begin{array}{l}
\text { dysarthric and } \\
\text { difficult to } \\
\text { understand }
\end{array}
\end{array}
$$

4 = functionally blind

Speech

Also score dystonia elsewhere: See Table 1

\section{Provoking Factor}

$0=$ nil

$1=$ reading and viewing or talking and eating

$2=$ movement of distant parts

$3=$ at rest

\section{Feeding}

$0=$ normal

$1=$ can still chew solids, occasionally chokes

2 = eats mainly soft foods, frequently chokes, but can feed

3 = significant difficulty

$4=$ can't feed 
TABLE 3

\section{WRITER'S CRAMP RATING SCALE}

\section{SUBJECTIVE}

$0=$ Normal

$1=$ Curious hand posture which could be interpreted as normal

$2=$ Obviously abnormal hand posture, but abnormalities confined to wrist and/or fingers

$3=$ Abnormal posture involves elbow and /or shoulder as well

$4=$ Abnormal posture involves other distant body parts, for example the neck (specify)
OBJECTIVE (using affected limb)

1 = Gibson's maze traced as accurately as possible given 30 or 60 seconds depending on pre-scoring trials

$2=$ Number of times the word "sunshine" can be written completely in one minute

$3=$ Number of counters piled on top of one another in one minute

$4=$ Ability to hold a full cup of water with arm outstretched (measured as the percentage of water split in one minute)

Dystonia elsewhere (not while writing) - see Table 1

and at intervals of $5,15,30,60,90$ and 120 minutes after the injection. Scoring was performed by an observer unaware of the drug administered, using rating scales devised for the involuntary movements (Marsden \& Schachter, 1981) (see Tables $1,2, \& 3$ ). Spasmodic torticollis was scored using estimates of the degree of turn, tilt and displacement in the sagittal plane, rating both tonic and spasmodic or clonic movements. Shoulder elevation and other abnormal postures and movements were also scored if present. Cranial dystonia was scored rating movements of eyelids, lips, jaw and tongue using the product of the degree of severity and the provoking factors as well as separate scores for vision, speech and feeding. Simple and dystonic writer's cramp were rated with a series of timed manoeuvres evaluating speed and accuracy of hand function, as well as scoring the severity of the abnormal postures and movements. Dystonia elsewhere was scored using a severity and provoking factor product for the parts of the body involved. At each rating time a second observer assessed blood pressure and pulse lying and standing and questioned the patient regarding side effects and their subjective rating of response to the injection.

For spasmodic torticollis and cranial dystonia the results were analysed by comparing changes in severity scores with averaged pre-injection control period ratings. The average overall change in score during the two hours post-injection was then expressed as a per cent improvement or worsening from the pre-injection mean score. Results for writer's cramp were analysed in a similar fashion but, the scores of each of the four motor tasks and the rating of writing disability were normalized on a scale of 0 to 10 before a composite figure was obtained.

2. Retrospective Chronic Oral Study

The notes of 93 patients with idiopathic spasmodic torticollis, 56 with cranial dystonia and 34 with writer's cramp were reviewed for a history of previous oral anticholinergic therapy (excluding tricyclic antidepressants and neuroleptics with anticholinergic properties). 38 patients with spasmodic torticollis, 25 with cranial dystonia, and 15 with writer's cramp had been treated with anticholinergic agents in varying doses at some time in the past. 63 patients had been treated with benzhexol. The mean dose in the 41 for whom this information was available was $11.6 \mathrm{mg}$ (range 4 $35 \mathrm{mg}$ ). Ten patients received orphenadrine in a mean dose of $300 \mathrm{mg}$ (range $150-600 \mathrm{mg}$ ) in the five where the dosage was known. Biperiden, procyclidine and benztropine were used in 1,4 and 6 patients respectively. Six patients had received two anticholinergic drugs at different times in the past. The response to therapy, as documented in the notes, was rated retrospectively as 1) a slight or mild, but definite improvement; 2) moderate improvement, still leaving obvious disability; 3) marked improvement with complete or almost complete resolution of dystonia. When response was shortlived or transient this also was recorded.

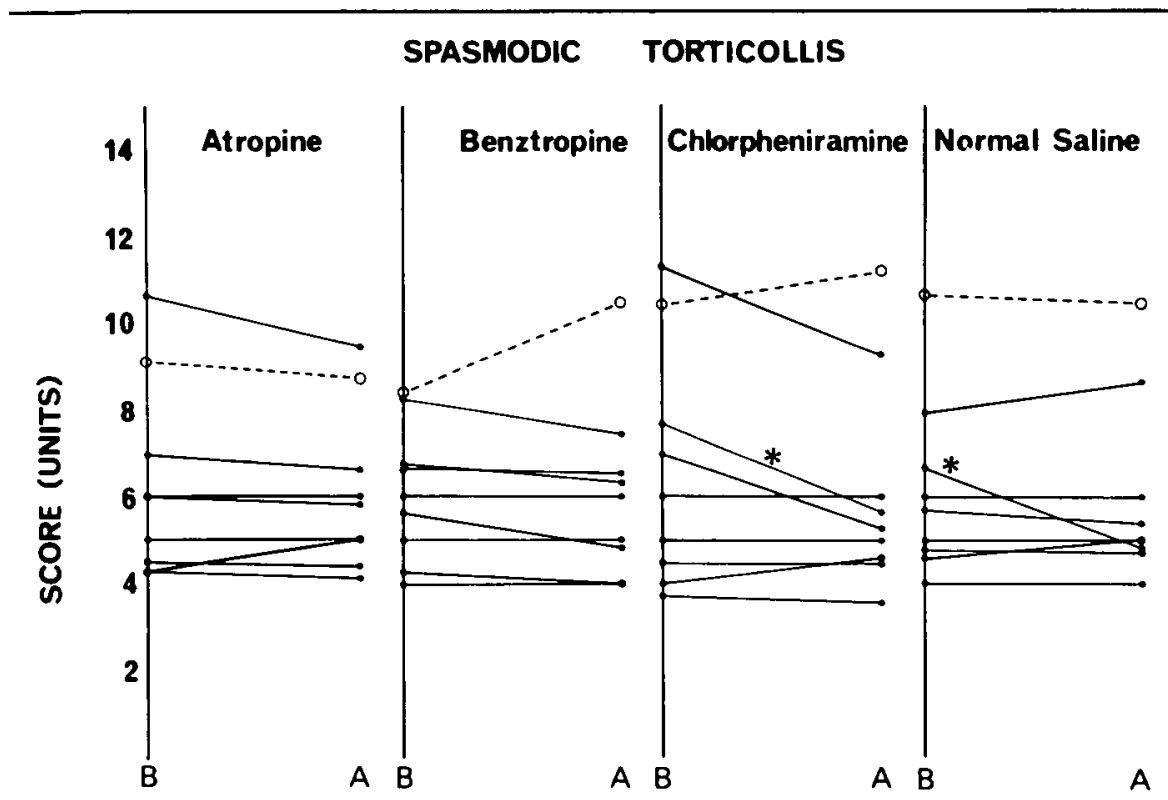

Figure 1 - Individual changes in rated score in 9 patients with spasmodic torticollis given intravenous injections of atropine $(0.6 \mathrm{mg})$ benztropine $(2 \mathrm{mg})$, chlorpheniramine $(10 \mathrm{mg})$ and normal saline. $\mathrm{B}=$ mean score over the 60 min pre-injection (i.e. "before"). $\mathrm{A}=$ mean score for the $2 \mathrm{hr}$. following the injection (i.e. "after"). The broken line gives scores of the patient with segmental dystonia reduced by a factor of 3 to fit the graph. * indicates the one patient improving (with chlorpheniramine) without sedation, but with similar benefit occurring after saline injection. 


\section{TABLE 4}

Effect of atropine ( $0.6 \mathrm{mg}$ i.v.), benztropine ( $2 \mathrm{mg}$ i.v.), chlorpheniramine (10 $\mathrm{mg}$ i.v.) and normal saline on spasmodic torticollis, cranial dystoni and writer's cramp

\begin{tabular}{|c|c|c|c|c|c|c|c|c|}
\hline & $\mathbf{n}$ & $\begin{array}{l}\text { Sex } \\
M / F\end{array}$ & $\begin{array}{c}\text { Mean age } \\
\text { (yrs) } \\
\text { (range) }\end{array}$ & $\begin{array}{c}\text { Duration of } \\
\text { dystonia (yrs) } \\
\text { (range) }\end{array}$ & Atropine & Benztropine & $\begin{array}{l}\text { Chlorpheni- } \\
\text { ramine }\end{array}$ & Saline \\
\hline Spasmodic torticollis & 9 & $5 / 4$ & $\begin{array}{c}40.5 \\
(22-58)\end{array}$ & $\begin{array}{c}5.4 \\
(2-11)\end{array}$ & -1.4 & -0.7 & -5.6 & -1.9 \\
\hline Cranial dystonia & 6 & $0 / 6$ & $\begin{array}{c}60.2 \\
(47-68)\end{array}$ & $\begin{array}{c}5.7 \\
(3-10)\end{array}$ & $+4.9 \mathrm{~b}$ & -15.6 & $-10.6 b$ & +12.1 \\
\hline Writer's cramp & 5 a & $4 / 1$ & $\begin{array}{c}46.8 \\
(35-66)\end{array}$ & $\begin{array}{c}12.4 \\
(4-23)\end{array}$ & -4.3 & -0.7 & +7.0 & -2.1 \\
\hline
\end{tabular}

Results are presented as mean per cent change in rated scores in the $2 \mathrm{hr}$ after i.v. drug injection, compared to the mean score during the 60 minute pre-injection period. Minus $=$ improvement, plus $=$ worsening.

None of these differences reached statistical significance (Wilcoxon's paired test).

$\mathrm{n}=$ number of patients

$\mathrm{a}=1$ patient with "simple" and 4 patients with "dystonic" writer's cramp

$\mathrm{b}=$ see text for dose alterations in one patient

\section{RESULTS}

\section{Acute intravenous administration} (Table 4)

\section{Spasmodic torticollis (Figure 1)}

Two of the nine patients with spasmodic torticollis showed improvement in their rated scores with normal saline of $28 \%$ and $6 \%$ respectively, and two worsened by $7 \%$ and $8 \%$, however, on average, there was no overall change. None of the three drugs caused any statistically significant change in the mean torticollis rated scores. Improvements of $10 \%$ or more occurred in 1 patient with atropine, 1 with benztropine, and 3 patients with chlorpheniramine. Drowsiness occurred in all those who improved, except in one patient who responded without sedation to chlorpheniramine, but who also improved equally to normal saline.

\section{Cranial dystonia (Figure 2)}

Only one of the 6 patients with cranial dystonia improved (by 4\%) with normal saline. Three worsened (by $13 \%, 19 \% \& 46 \%$ respectively) and, on average, there was a $12 \%$ deterioration although this did not reach statistical significance. None of the three drugs caused any statistically significant change in the mean cranial dystonia rating scores. Four patients improved by more than $10 \%$ on either benztropine or chlorpheniramine, but such benefit was associated with sedation in three of the four patients responding, most obvious in the two with the greatest change in rated scores.
Writer's cramp (Figure 3)

Three of the five patients with writer's cramp showed some improvement with normal saline (by 3 to $7 \%$ ), but the mean change in rated score was only $2.1 \%$. No patient exhibited an overall improvement of more than $10 \%$

\section{CRANIAL DYSTONIA}

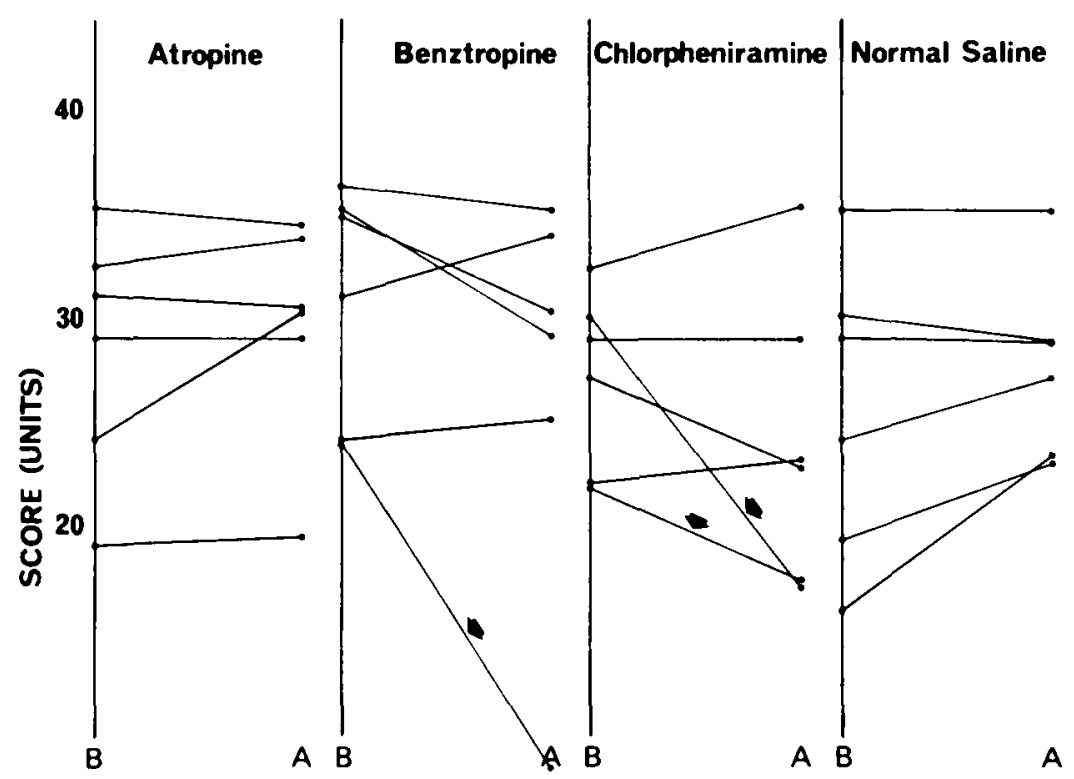

Figure 2 - Individual changes in rated score in 6 patients with cranial dystonia given intravenous injections of atropine $(0.6 \mathrm{mg})$, benztropine $(2 \mathrm{mg})$, chlorpheniramine $(10 \mathrm{mg})$ and normal saline. Arrows indicate those patients who developed obvious sedation. ("B" and " $A$ " as in Figure 1). 
and there was no change in the rating of the dystonic posture adopted when writing with any of the drugs. The two patients whose performance deteriorated with chlorpheniramine became drowsy.

\section{Other observations}

Aside from drowsiness, the only other unwanted effects noted were a dry mouth with all three drugs, and occasional faintness without observed change in blood pressure. The pulse increased by an average of 14 beats per minute within 30 minutes of atropine injection, but did not alter with benztropine and chlorpheniramine.

\section{Chronic administration (Table 5)}

Only 17 of the 78 patients treated with chronic oral anticholinergic drugs obtained any documented useful benefit from these drugs ( 9 of 38 with spasmodic torticollis, 4 of 25 with cranial dystonia, and 4 of 15 with writer's cramp). Eight had a moderate to marked improvement, but within days to weeks the movements returned to their original severity in two patients (1 with cranial dystonia, 1 with torticollis), and the benefit was reduced to mild in a third (with torticollis). Four patients ( 3 with cranial dystonia and 1 with torticollis) reported an increase in their symptoms with anticholinergic therapy. The dosage of anticholinergic drug did not appear to differ between patients improving and the entire group.

\section{DISCUSSION}

This study was undertaken to evaluate the effectiveness of three anticholinergic drugs with somewhat differing central actions on adult onset focal dystonias. These drugs, however, did not have a dramatic effect in spasmodic torticollis, cranial dystonia, and writer's cramp. The drugs either were of no benefit, or occasionally lessened the severity of the dystonia because they caused sedation.

We have been unable to reproduce the findings of two previous studies using acute parenteral administration of anticholinergics in spasmodic torticollis. Tanner et al $(1979,1979 a)$ obtained a response to scopolamine which was

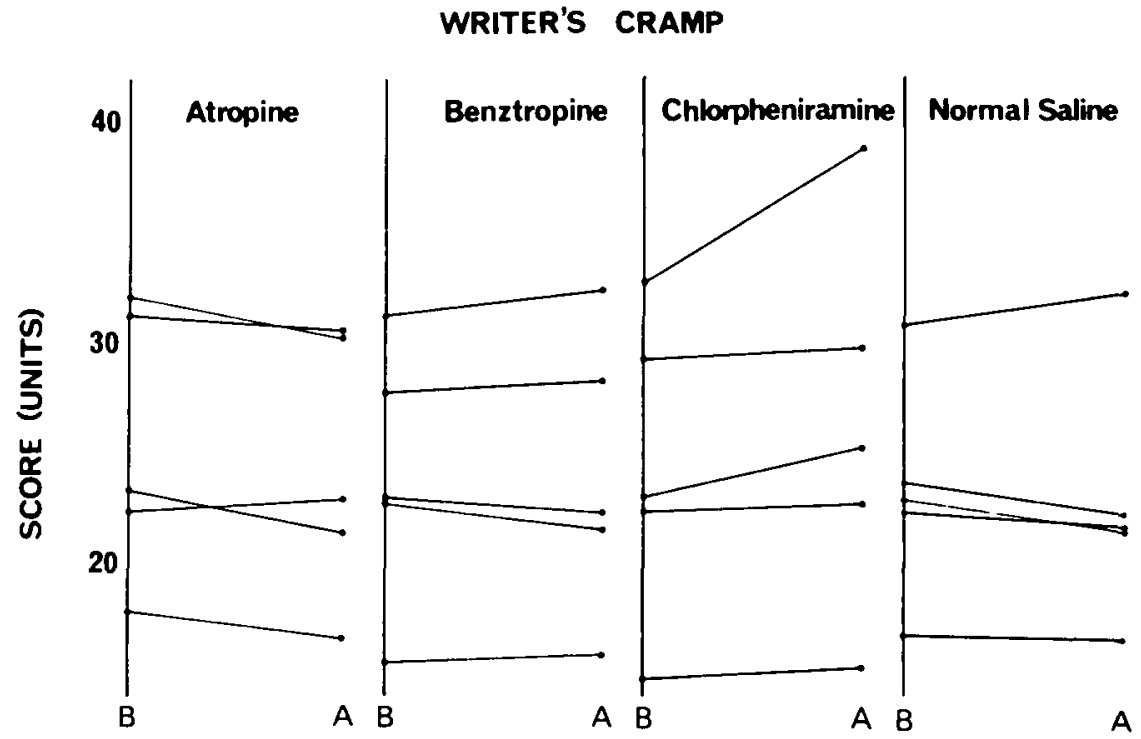

Figure 3 - Individual changes in normalized rated score in 5 patients with writer's cramp ( 1 with simple writer's cramp, 4 with dystonic writer's cramp) given intravenous injections of atropine $(0.6 \mathrm{mg})$, benztropine $(2 \mathrm{mg})$, chlorpheniramine $(10 \mathrm{mg})$ and normal saline control. Because a decrease in the score of the individual manoeuvres indicated improvement on some tests and worsening on others, the scores of each individual were normalized on a 0 to 10 scale $(0=$ normal, $10=$ maximum abnormality) and then summed to give a final score. (" $B$ " and " $A$ " as in Figure 1).

TABLE 5

Chronic Oral Anticholinergic Drug Therapy in Idiopathic Focal Dystonia

\begin{tabular}{|c|c|c|c|c|c|}
\hline & \multicolumn{5}{|c|}{ Benefit } \\
\hline & $\mathbf{n}$ & None & Mild & Moderate & Marked \\
\hline Spasmodic Torticollis & 38 & $\begin{array}{c}29 \\
\left(W_{1}\right)\end{array}$ & $\begin{array}{c}6 \\
\left(T_{1}\right)\end{array}$ & 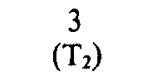 & - \\
\hline Cranial Dystonia & 25 & $\begin{array}{c}21 \\
\left(W_{3}\right)\end{array}$ & 1 & 1 & $\begin{array}{c}2 \\
\left(\mathrm{~T}_{1}\right)\end{array}$ \\
\hline Writer's Cramp & 15 & 11 & 2 & 1 & 1 \\
\hline Totals & 78 & $\begin{array}{c}61 \\
\left(W_{4}\right)\end{array}$ & $\begin{array}{c}9 \\
\left(\mathrm{~T}_{1}\right)\end{array}$ & $\begin{array}{c}5 \\
\left(T_{2}\right)\end{array}$ & $\begin{array}{c}3 \\
\left(T_{1}\right)\end{array}$ \\
\hline
\end{tabular}

uniformly antagonised by physostigmine in all of the six patients they studied. Only single ratings were performed with each injection and, although a saline control was used, the various drugs were not given in a random double blind fashion. Lal et al (1979) noted a response to intravenous benztropine in six of thirteen patients, five of whom later improved on similar chronic oral therapy. Neither group discussed the possible natural variability of the abnormal movements, but Lal and his colleagues (1981) more recently recognized considerable variability in the severity of torticollis. In both studies, "blind" rating was performed only by means of video tape or film. These rating methods, although convenient and useful for documentation, may not allow complete and sensitive rating of changes in the severity of the involuntary movements. For example, in patients with spasmodic torticollis our rating was performed from multiple different angles, and the aggravating effects of various manoeuvres such as walking and the use of 
the hands was also taken into consideration.

A prospective double-blind study investigating the effects of oral anticholinergics in spasmodic torticollis has yet to be performed. Our review of patient's notes is open to all the criticisms of a retrospective study. However, if patients had obtained more than mild benefit, the response would have been noted, and such patients would have continued with the drug if improvement was sustained. Our results with oral anticholinergic therapy in spasmodic torticollis do not agree with those of Lal et al (1979). Five of their ten patients treated with oral benztropine $(2-8 \mathrm{mg})$ obtained sustained improvement, while only one of our 38 patients had more than mild prolonged benefit.

The neuropharmacology of cranial dystonia also is controversial. In the only double-blind controlled trial of oral anticholinergics in cranial dystonia, Nutt et al (1982) obtained disappointing results with benzhexol (4-12 mg per day) in 5 patients despite promising results in an earlier open study. Gollomp et al (1982) found that 3 of 15 patients were improved with oral anticholinergics, but only in combination with other drugs. One of the two patients treated by Casey (1980) with oral benztropine worsened, while the other remained unchanged. Altrocchi (1972) obtained an improvement with benztropine $4 \mathrm{mg}$ intravenously in one patient with subsequent transient mild improvement on oral therapy. Four of five patients treated by Tanner et al (1981) improved with acute scopolamine and worsened with physostigmine, while chronic anticholinergic treatment resulted in "long-term" partial improvement in 4 of the scopolamine responders and in 3 of the others. Tolosa and Lai (1979) found the movements to be aggravated by physostigmine, while benztropine reversed this deterioration; however, the effect of anticholinergic agents alone was not studied. Many of these reports evaluated small numbers of patients, and did not use a double-blind placebo controlled rating system. In addition to the six patients studied in the present trial, we also have given benztropine 2 mg intravenously in an open fashion to two other cranial dystonia patients with no alteration in their movements. These results, and our experience with oral anticholinergic therapy in 25 patients with cranial dystonia, do not suggest a convincing general cholinergic neuropharmacological mechanism underlying this condition.

The neuropharmacology of simple and dystonic writer's cramp has not been investigated previously. Although the response to acute intravenous anticholinergic drugs was disappointing, a higher proportion of this group obtained some benefit from oral anticholinergics than in the other types of focal dystonias. The incomplete nature of the response, however, suggests that cholinergic mechanisms also are not of prime importance in the pathogenesis of this disorder.

The generally negative findings in this study must be viewed against the undoubted experience that the occasional patient with focal or generalized dystonia may respond convincingly to chronic oral anticholinergic drug therapy. This suggests that the idiopathic dystonias may be pharmacologically heterogeneous. The children with torsion dystonia reported by Fahn (1982) to show a striking response were all treated with gradually increasing high oral doses of anticholinergic drugs. The acute intravenous administration of anticholinergics does not allow adaptation to unwanted effects, such as changes in awareness, that may limit dosage. In addition, chronic high dose oral therapy could alter the activity of other neurotransmitter systems, either by direct action or through gradually evolving compensatory mechanisms. Properly designed placebo-controlled double-blind studies of the effect of chronic oral anticholinergic drugs in focal dystonias are required to determine if such treatment is beneficial.

\section{ACKNOWLEDGEMENTS}

These studies were supported by the Dystonia Research Foundation, the Medical Research Council, and the research funds of the Bethlem Royal and Maudsley Hospitals and King's College Hospital. Dr. Lang is a Fellow of the Medical Research Council of Canada, and Dr. Sheehy is supported by the Parkinson's Disease Society of Great Britian.

\section{REFERENCES}

ALTROCCHI, P.H. (1972) Spontaneous oralfacial dyskinesia. Arch. Neurol. 26: 506512.

BURKE, R.E., FAHN, S., JANKOVIC, J., MARSDEN, C.D., LANG, A.E., GOLLOMP, S., ILSON, J. (1982) Tardive Dystonia: Late-onset and persistent dystonia caused by neuroleptic drugs. Neuro$\operatorname{logy}(\mathrm{Ny})$ (in press).

CASEY, D.E. (1980) Pharmacology of blepharospasm - oromandibular dystonia syndrome. Neurology, 30: 690-695.

COYLE, J.T. and SNYDER, S.H. (1969) Antiparkinsonian drugs: inhibition of dopamine uptake in the corpus striatum as a possible mechanism of action. Science 166: 899-901.

FAHN, S. (1982) High dosage anticholinergic therapy in dystonia. Adv. Neurol. (in press) Raven Press, New York.

FUXE, K., GOLDSTEIN, M. and LUNGDAHL, A. (1970) Antiparkinsonian drugs and central dopamine neurones. Life Sci. 9 pt 1:811-824.

GOLLOMP, S., FAHN, S., BURKE, R.E., RECHES, A., ILSON, J. (1982) Therapeutic trials in Meige Syndrome. Adv. Neurol. (in press) Raven Press, New York.

LAL, S., HOYTE, K., KIELY, M.E., SOURKES, T.L., BAXTER, D.W., MISSALA, K. and ANDERMAN, F. (1979) Neuropharmacological investigation and treatment of spasmodic torticollis. In: Adv. Neurol. 24, Eds. L.J. Poirier, T.L. Sourkes and P.J. Bedard. 335-351, Raven Press, New York.

LAL, S., YOUNG, S.N., KIELY, M.E., HOYTE, K., BAXTER, D.W., SOURKES, T.L. (1981) Effect of L-Tryptophan on Spasmodic Torticollis. Can. J. Neurol. Sci. 8: 305-308.

MARSDEN, C.D. (1976) Blepharospasmoromandibular dystonia syndrome (Brueghel's syndrome). A variant of adult-onset torsion dystonia? J. Neurol. Neurosurg. Psychiatry. 39: 1204-1209.

MARSDEN, C.D. (1976a) The problem of adult-onset idiopathic torsion dystonia and other isolated dyskinesias in adult life. Adv. Neurol. 14, Ed. R. Eldridge and S. Fahn. 259-276, Raven Press, New York.

MARSDEN, C.D. and SCHACHTER, M. (1981) Assessment of extrapyramidal disorders. Br. J. Clin. Pharmac. 11: 129-151.

MARSDEN, C.D., TARSY, D., BALDESSARINI, R.J. (1975) Spontaneous and drug-induced movement disorders in psychotic patients. In: Psychiatry Aspects of Neurological Disease. Ed. F.D. Benson and D. Blumer 219-266, Gune and Stratton, New York. 
MELDRUM, B.S., ANLEZARK, G.M. and MARSDEN, C.D. (1977) Acute dystonia as an idiosyncratic response to neuroleptics in baboons. Brain 100: 313-326.

NUTT, J.G., HAMMERSTAD, J.P., CARTER, J.H., deGARMO, P.L. (1982) Treatment of Meige's syndrome with Artane. Adv. Neurol. (in press), Raven Press, New York.

TANNER, C.M., GLANTZ, R.H., KLAWANS, H.L. (1981) Meige Syndrome (Ble- pharospasm/oromandibular dystonia syndrome): Analysis of the clinical pharmacology in 12 patients. Neurology $31: 78$.

TANNER, C.M., GOETZ, C.G. and KLAWANS, H.L. (1979) Cholinergic mechanisms in movement disorders: results of physostigmine and scopolamine administration. In: Nutrition and the Brain, vol. 5, Ed. A. Barbeau, J.H. Growdon and R.J. Wurtman, 273-284, Raven Press, New York.
TANNER, C.M., GOETZ, C.G., WEINER, W.J., NAUSIEDA, P.A., WILSON, R. and KLAWANS, H.L. (1979a) The role of cholinergic mechanisms in spasmodic torticollis. Neurology 29,604-605.

TOLOSA, E.S. and LAI, C. (1979) Meige disease: striatal dopaminergic preponderance. Neurology 29: 1126-1130.

ZEEMAN, W. (1970) Pathology of the torsion dystonias (dystonia musculorum deformans) Neurology 20: Pt 2: 79-88. 